\title{
A relevância política de alguns princípios do Contato Improvisação
}

\section{The political relevance of some principles of Contact Improvisation}

Pedro Rodrigo Penuela Sanches ${ }^{1}$ 


\section{Resumo}

Neste trabalho discutimos implicações éticas e políticas que caracterizam a forma de dança conhecida no Brasil como Contato Improvisação, destacando a relevância dos princípios que embasam os seguintes aspectos desta: 1 . A dilatação do tempo e a sutilização da percepção, 2. A questão da resistência (ou a resistência em questão), 3. A ruptura com o imperativo da produtividade, 4. A questão (aberta) da comunidade, dos laços coletivos e dos espaços de refúgio. Examinando cada um destes aspectos, salientamos como esta forma de dança subverte os imperativos culturais hegemônicos da aceleração da ação, da densificação da estimulação e da produtividade, bem como permite problematizar e complexificar a noção de resistência e as estratégias de contraposição política e cultural a um status quo, criando, assim, espaços de compartilhamento sui generis, articulados por uma percepção comum e por "verdades éticas" orientadoras do encontro e das relações.

Palavras-chaves: Contato Improvisação; dança e política; percepção
This paper addresses some ethical and political implications of the dance form called Contact Improvisation, focusing on the relevance of some of its principles regarding: 1 . The dilatation of time and subtilization of perception; 2 . The question of resistance (or the resistance under questioning); 3 . The rupture with the productivity imperative; 4 . The (open) question of community, collective binds and spaces of refuge. Examining each one of those aspects, we underline how this dance form contributes to subvert a hegemonic culture of acceleration, densification of stimulation, and productivity, as well as it can complexify the notion of resistance and political strategies of confrontation against a status quo, thus, creating specific spaces of sharing and meeting articulated by a common perception and "ethical truths".

Keywords: Representation criticism; theaters of the real; aesthetical regime; biodrama; endless representation

E-ISSN: 2358.6958

\footnotetext{
1 Doutorando pelo Programa de Pós-Graduação em Artes Cênicas - Universidade de São Paulo (PPGAC - ECA - USP), com bolsa da Fundação de Amparo à Pesquisa do Estado de São Paulo (FAPESP). pedro.penuela@gmail.com
} 


\section{Contato Improvisação e seus princípios}

A forma de dança conhecida no Brasil como "Contato Improvisação"2 caracteriza-se por propor uma situação de diálogo entre corpos baseada na mútua sintonização destes com as forças e princípios físicos que os constituem e atravessam, em especial com o peso e a gravidade, como também com a inércia, o momentum, alavancas, vetores, entre outros aspectos mecânicos do movimento. A partir dessa sintonização com a "fisicalidade", os corpos envolvidos podem engajar-se em uma improvisação conjunta.

Ao longo de sua recente história, muitas diferentes definições foram propostas para essa forma de dança, ao mesmo tempo em que seus criadores procuraram defender seu caráter aberto e em constante elaboração e transformação. Steve Paxton (1939-), dançarino norte-americano reconhecido como principal criador do Contato Improvisação, o descreve como:

Um modo de movimento que é relaxado, constantemente consciente e preparado, e no fluxo. Como um foco básico, os bailarinos permanecem em contato físico, mutuamente dando-se apoio e inovando, meditando sobre as leis físicas relacionadas às suas massas: gravidade, momentum, inercia y fricção. Eles não buscam chegar a resultados, mas encontrar a realidade física que muda constantemente com a localização e a energia adequadas. (Paxton, 1979)

O surgimento dessa forma de dança deu-se nos EUA a partir dos desdobramentos de uma oficina dada por Paxton no Oberlin College, em 1972, que resultou em uma performance denominada "Magnesium".

Antes deste evento, Paxton já acumulava uma consistente experiência no desenvolvimento da abordagem "pós-moderna" (cf. Banes, 1987) da dança nos EUA, tendo sido dançarino da companhia de Merce Cunningham, assim como participado da criação e desenvolvimento dos coletivos de experimentação Judson Dance Theater e Grand Union, que se revelaram altamente transformadores e férteis como fonte de pesquisas ulteriores de seus membros ${ }^{3}$.

$\mathrm{Na}$ oficina que deu em 1972 e na performance resultante, Magnesium, Paxton compartilhou suas investigações sobre distintos modos de o corpo resolver instantaneamente situações extremas como quedas e colisões e sobre o que ele denominaria "Pequena dança", que descreveremos adiante.

Alguns dançarinos que participaram ou que assistiram a esta performance propuseram a Paxton colaborar dando continuidade a essa investigação, iniciando assim

\footnotetext{
2 Trata-se da tradução mais disseminada no país da expressão em inglês Contact Improvisation. Em outras ocasiões (Penuela Sanches, 2015) discuti que "improvisação em contato" seria uma tradução mais precisa. No entanto, cedendo ao uso costumeiro, neste trabalho mantemos a expressão "Contato Improvisação", à qual também substituiremos, neste artigo, frequentemente, pela abreviação "Cl".

3 O Judson Dance Theater surgiu em 1962 a partir de uma aula de composição dada pelo músico Robert Dunn, que trabalhava com Merce Cunningham, em grande parte com experimentações ligadas às propostas do músico John Cage, especialmente os procedimentos de composição a partir do acaso (cf. Novack, 1990, p. 43 e 53). O espaço utilizado pelo coletivo era cedido por uma igreja de Nova York, e diferentemente das companhias de dança tradicionais, o Judson tinha uma estrutura de criação horizontal e flexível e era aberto à participação de artistas de diferentes linguagens e não profissionais. Dele participaram alguns dos principais criadores da dança pós-moderna, como Steve Paxton, Trisha Brown, Yvonne Rainer, Deborah Hay, entre outros. Já o Grand Union se desenvolveu a partir do projeto de Yvonne Rainer, Continuous Project - altered daily, quando esta começou a deixar seu papel de coreógrafa e o grupo passou a funcionar como um coletivo de experimentação a partir de propostas trazidas por cada um dos membros. Esteve em atividade de 1970 a 1976. (cf. Banes, 1987)
} 
um processo contínuo de apresentações e propostas de investigação que formaria uma forma de dança reconhecível, caracterizada por certos princípios de abordagem do corpo e do movimento e por certas escolhas e implicações estéticas, éticas, epistemológicas e políticas ${ }^{4}$.

Cynthia Novack (1990), antropóloga que investigou essa forma de dança e sua relação com a cultura norte-americana, considera que seus princípios básicos de abordagem da corporeidade e do movimento seriam: 1. Gerar movimento por meio dos pontos em contato entre os corpos (Novack, 1990, p. 116); 2. Sentir por meio da pele, de modo a usar toda a sua superfície como apoio para a troca de peso e comunicação e sintonização com o outro; 3 . Rolar através do corpo, segmentando-o e sendo capaz de mover-se em várias regiões simultaneamente, com múltiplos focos, o que "permite mais opções na improvisação com um parceiro e aterrissagens mais suaves" (Novack, 1990, 118); 4. Experimentar o movimento "desde dentro", isto é, com o foco nas sensações e na propriocepção; 5. Abordagem do espaço em 360, sem privilégio de uma frontalidade, bem como uso de caminhos circulares e espiralados para o movimento; 6. "Seguir o momentum 5 , enfatizando o peso e o fluxo" (Novack, 1990, p. 121), o que implica em permitir a continuidade do movimento sem necessariamente saber onde ou como ele vai terminar; 7. Informalidade e "inclusão tácita do público"6; 8. "Deixar a dança acontecer", ou seja, enfatizar o caráter improvisacional e a abertura a não saber como uma dança se desenvolverá; 9. Desierarquização dos participantes (no sentido de não haver papéis ou signos alusivos a uma maior ou menor importância dos participantes de uma performance).

Diferentes autores da filosofia e da teoria da dança têm discutido as implicações estéticas, éticas e políticas do modo singular de abordar a dança manifesto nesses princípios e na prática do $\mathrm{Cl}$ em geral.

O filósofo José Gil, por exemplo, discute como as experiências e a abordagem do corpo que emergem no $\mathrm{Cl}$ podem transformar as compreensões clássicas da comunicação intersubjetiva e da relação entre corpo e consciência, na medida em que a própria consciência transforma-se, segundo ele, de "consciência do corpo" para "corpo de consciência", adquirindo a plasticidade e multifocalidade próprias do modo como o corpo atua e percebe ao improvisar (cf. Gil, 2004, p. 125).

Por fim, Gil reflete sobre como os princípios do $\mathrm{Cl}$ implicam um projeto, talvez impossível de se completar, de abolição de "tudo o que é da ordem da dominação ou manipulação das consciências" (Gil, 2004, p. 125).

Já a filósofa Marie Bardet, por sua vez, enfatiza como a movimentação gerada por uma dança baseada na sensação, como seria o caso do $\mathrm{Cl}$, no deslizar sobre o solo e no aproveitamento de toda a superfície da pele implica um trabalho de de-

\footnotetext{
4 Mais sobre a história do Cl pode ser encontrado em: Novack, 1990; Penuela Sanches, 2012.

5 Momentum é um termo da mecânica que se refere às forças e à inércia em um sistema de movimento em rotação. No contexto do Contato Improvisação este termo tende a ser usado em um sentido mais amplo, como forma de nomear uma continuidade de movimento com aplicação mínima possível de esforço ou impulso, ou seja, uma continuidade baseada no aproveitamento da inércia, da tendência de manutenção de determinado estado de movimento.

6 Em relação às performances de $\mathrm{Cl}$, sobretudo no momento inicial de seu desenvolvimento, na década de 1970, a autora salienta o princípio, já presente na maior parte dos trabalhos do Grand Union e do Judson Dance Theater, de não usar recursos teatrais de iluminação cênica, figurino especial etc. assim como o estabelecimento de um espaço em geral circular, e não frontal, sem divisões espaciais claras entre o público e os dançarinos (muitas vezes com o público sentado no chão, ao redor de onde os dançarinos movem-se), o que também se relaciona com uma concepção do dançarino como "si mesmo", "só uma pessoa", sem representar um personagem e podendo tossir, arrumar a roupa, parar para descansar, etc.
} 
sierarquização do corpo em direção a uma abordagem em que as partes de trás dos joelhos, os tornozelos, etc. podem ser um campo tão complexo de semiotização e sensação quanto o rosto ou as mãos, e a própria distribuição do peso pode permitir-se arquiteturas totalmente plásticas e diversas em relação à distribuição cotidiana civilizada habitual (Bardet, 2014, p. 110).

Além disso, refletindo sobre a improvisação, Bardet enfatiza de que modo esta subverte uma noção de ação baseada na separação entre sujeito e objeto, ou na dicotomia entre preparação/pensamento, de um lado e ação/execução, de outro. (Bardet, 2014, p. 162).

Já Laurence Louppe, (2012), uma das mais importantes teóricas da dança contemporânea, também enfatiza a relevância do $\mathrm{Cl}$ para a história e constituição da dança contemporânea, sobretudo por seu modo próprio de abordar o peso, afirmando que:

\begin{abstract}
O interesse do contact é, antes de mais, reencontrar a essência da dança, assim designada por Laban e identificada como a primazia do peso. Neste contexto, a opção gravítica prevalece sobre todas as decisões voluntárias de peso. O movimento é determinado pelas modalidades de troca de peso interior e de intercâmbio com o outro. As consequências qualitativas para a formação do bailarino são inestimáveis: a familiaridade com a instabilidade, a libertação da verticalidade objetiva, uma relação multidimensional com o espaço, a atenção ao corpo do outro e ao desconhecido que, devido à perda das coordenadas racionais e espaciais, não podemos antecipar e ainda menos aligeirar. (Louppe, 2012, p. 237)
\end{abstract}

Em suma, como as reflexões e considerações dos autores citados evidenciam, o conjunto de princípios e modos de abordar a corporeidade, a sensorialidade, o movimento e as relações entre corpos que constitui o Contato Improvisação tem uma importância e implicações bastante contundentes, na medida em que desconstroem ou transformam na prática alguns dos fundamentos de uma constituição dicotômica, instrumental, objetificante e mecanizante do corpo na modernidade.

Passemos então ao debate mais específico sobre algumas outras de suas implicações políticas. Para isso, pretendemos refletir a partir dos seguintes aspectos: 1. A dilatação do tempo e a sutilização da percepção, 2. A questão da resistência (ou a resistência em questão), 3. A ruptura com o imperativo da produtividade, 4. A questão (aberta) da comunidade, dos laços coletivos e dos espaços de refúgio.

\title{
A dilatação do tempo e a sutilização da percepção
}

Muitos diferentes autores têm refletido sobre a constituição, na modernidade, e sobretudo a partir da industrialização, de uma temporalidade baseada na valorização da velocidade, na aceleração dos processos em geral, na uniformização dos ciclos e ritmos vitais e na densificação da estimulação e da informação.

Georg Simmel (1902), por exemplo, ao refletir sobre a vida nas cidades ao final do século XIX e começo do século XX, aponta como a "intensificação dos estímulos nervosos", (Simmel, 1902, p. 12), isto é, o crescimento constante da quantidade de informações e apelos sensacionais de diversos tipos, aliado à lógica homogeneizadora 
da economia monetária, implica numa progressiva dessensibilização dos sujeitos, no sentido em que, habituados cada vez mais com quantidades maiores de estímulos em um menor período de tempo, os habitantes da cidade passam a necessitar de estímulos cada vez mais intensos e em maior quantidade para reconhecê-los e considerá-los dignos de atenção, o que, com o tempo, constitui o que este autor denomina de "atitude blasé" (Simmel, 1902, pp. 15-17), isto é, um modo de ser e estar no mundo cada vez menos capaz de sensibilizar-se com os acontecimentos à sua volta e cada vez mais anestesiado pela banalização e homogeneização das experiências.

Marshall Berman (1982) e Zygmunt Bauman (2000), por sua vez, desdobrando o pensamento de Karl Marx cada um a seu modo, apontam como a sociedade e a economia capitalistas constituem-se com base em um processo constante e cada vez mais intenso de liquefação do que é sólido e de diminuição da durabilidade dos objetos (a fim de que eles cada vez mais aceleradamente entrem no fluxo incessante de produção, comércio, consumo e descarte de mercadorias) e também das relações, modos de vida, estruturas urbanas e de sociabilidade, etc.

Fenômenos diversos como a obsolescência programada das mercadorias, a criação e disseminação artificiosas de necessidades que antes não existiam, a fragilidade e instabilidade crescentes dos vínculos sociais e afetivos e a degradação de ecossistemas pelas pressões cada vez maiores da produção e do consumo podem ser descritos e compreendidos a partir dessa tendência geral de liquefação e redução das durações e permanências, em nome do incremento dos processos de produção, comércio e consumo que sustentam o capitalismo.

Walter Benjamin $(1933,1936)$, por sua vez, examina ainda esses mesmos fenômenos (a industrialização, a urbanização e a consolidação de uma economia baseada num fluxo constante e em constante aceleração de produção e consumo), enfatizando como os predomínios da informação por sobre a narrativa e dos modos de produção industrial por sobre os modos de produção artesanal implicam num empobrecimento ou na própria impossibilidade da experiência, na medida em que esta depende de sua articulação com a memória, dada pela narrativa, e com uma experiência mais ampla de sentido, que está em contradição com o fluxo incessante de acontecimentos sempre aparentemente diferentes, mas por outro lado sempre os mesmos, que caracterizam o modo de produção capitalista.

Autores contemporâneos seguem desdobrando esse diagnóstico da aceleração e da liquefação como características estruturantes de nossa sociedade, apontando, por exemplo "a generalização do sentido de urgência", nas palavras de Daniel Innerarity (2012) ou a perda da narrativa e a atomização da experiência, como faz Byung-Chul Han (2016), ecoando Benjamin, como constituintes problemáticos dos modos hegemônicos de relação com o tempo em nossa sociedade.

No âmbito da constituição dos corpos, Denise Sant'Anna (2001) salienta a preponderância da concepção do espaço na sociedade contemporânea cada vez mais restrito à qualidade de espaço de fluxo e de passagem, onde situações e estados de permanência, pausa e suspensão são crescentemente impedidos ou impossibilitados.

Uma das implicações dessa concepção do espaço em associação intrínseca com a velocidade dos fluxos é a consideração do peso dos corpos como um inimigo e um obstáculo a ser superado e aniquilado, na medida em que o peso estorva a utopia da 
máxima velocidade (Sant'Anna, 2001, p. 19).

Contrariamente, o Contato Improvisação, assim como a obra de Steve Paxton em geral, propõe modos de experienciar as sensações e a corporeidade que se contrapõem à aceleração do tempo e à banalização da estimulação sensorial e da experiência.

Antes ainda do desenvolvimento do $\mathrm{Cl}$, Paxton passou grande parte dos anos 1960 investigando atentamente ações cotidianas e comuns, sobretudo o caminhar. Em peças como Flat (1964) e Satisfying lover (1967), Paxton colocou ações consideradas banais no espaço teatral, tensionando as fronteiras presentes nos modos como o senso comum e parte da filosofia compreendem as diferenças entre naturalidade e artificialidade, cena e cotidiano, ficção e realidade. Em suas palavras a respeito desse período de sua obra:

\begin{abstract}
Quanto mais eu treinava meu corpo, mais eu tinha esta questão: O que ele está fazendo quando eu não o estou treinando, e pensando sobre isso e sendo... cultivando essa consciência em meu cérebro? [...] então isso implicou, em trabalhos como Flat, em prestar atenção a detalhes muito pequenos, e eu fiquei interessado em coisas como o modo como alguém amarra os cadarços dos sapatos, como se veste e se desveste, e pô-las em cena significava que os detalhes estavam sob um escrutínio mais preciso [...]. Assim, eu estava construindo performances baseadas em olhar cuidadosamente para coisas comuns, e isso durou dez anos. (Paxton, 20177)
\end{abstract}

Paxton aponta com bastante clareza que o exame detalhado e dilatado no tempo das coisas comuns e consideradas banais implica uma transformação bastante radical da percepção: “O ordinário é num certo sentido, não-visível, invisível, porque é... ordinário. Os sentidos o sintonizam para fora [...]. Você não precisa notá-lo. Você não precisa vê-lo" (Paxton, 1989, p. 15).

Direcionar a atenção para o que é considerado básico e banal e reexaminá-lo suspendendo as certezas do hábito e abrindo um espaço de indagação e de espanto é um gesto com implicações contundentes, por várias razões. Uma delas é justamente o modo como tal gesto se opõe à banalização da experiência e à "atitude blasé" que mencionamos anteriormente.

Se a constante estimulação banaliza experiências e se essa banalização serve a uma economia do consumo, na medida em que alimenta a necessidade por sensações "novas" e sempre mais intensas, voltar-se ativamente para as coisas invisibilizadas rompe esse ciclo. Pois, ao abrir-se a possibilidade de o banal ser redescoberto e reexaminado, abre-se, por conseguinte, a possibilidade de a realidade ser percebida de modos completamente diversos do habitual, e de as sensações e experiências revelarem sentidos e existências diversas. Assim, o que parecia fixo em seu caráter de coisa óbvia e natural pode ser questionado e transformado.

O combate a injustiças e problemas estruturais em nossa sociedade, tais como o machismo, o racismo, as opressões sobre as diversidades de gênero e orientação sexual, as opressões de classe, a desigualdade econômica e social, a destruição de

7 Em entrevista para o autor a ser publicada futuramente. 
modos de vida diversos do hegemônico, entre outras, depende, entre outras coisas, da possibilidade de desnaturalizar experiências e fenômenos amiúde sutis, habituais, e concebidos pelo senso comum como óbvios ou banais. Nesse sentido, a atuação sobre o modo como percebemos o mundo e as coisas cotidianas tem implicações políticas de grande importância.

Além disso, com o desenvolvimento do Contato Improvisação e das pesquisas de Paxton, a atenção às coisas comuns e "ordinárias", que caracterizou seu trabalho nos anos 1960, desdobrou-se em uma proposta de expansão da atenção e das possibilidades de percepção e conhecimento para fenômenos muito sutis e pequenos, que constituem a corporeidade e o movimento, de modo a incluí-los no campo do que é considerado dança e arte. Um dos exemplos mais significativos é o que Paxton denominou "a pequena dança". Trata-se de um modo de nomear os micromovimentos que podem ser observados sob a instrução de relaxar o máximo possível a musculatura, mas ainda assim mantendo-se em pé. Em suas palavras:

No próprio fato de você estar pedindo a si mesmo para relaxar e ainda assim continuar em pé - encontrando esse limite no qual você não poderia relaxar mais sem cair, você é posto em contato com um esforço de sustentação básico que acontece constantemente no corpo, do qual você não tem de estar consciente. É um movimento de fundo, que você desconsidera para enfocar suas atividades mais interessantes. Ainda assim ele está sempre aí sustentando você. Estamos tentando entrar em contato com esse tipo de forças primárias no corpo e fazê-las prontamente aparentes. Eu chamo isso de 'a pequena dança'... Foi um nome escolhido principalmente porque é bastante descritivo da situação e porque enquanto você está fazendo o ficar em pé e sentir a 'pequena dança' você se dá conta de que não está 'fazendo' isso, então, de certo modo você está se assistindo fazer [perform]; assistindo seu corpo executar sua função. E sua mente não está resolvendo nada e não está procurando por nenhuma resposta ou sendo usada como um instrumento ativo, mas está sendo usada como uma lente para enfocar certas percepções. (Paxton, 1977/1997, p. 23)

A prática da "pequena dança" abriu um espaço de investigação da percepção de fenômenos e movimentos muito sutis e pequenos, ampliando a abrangência da percepção e das noções de movimento e de dança ${ }^{8}$. Além disso, ela desdobra a problematização da autoria e da noção de agenciamento baseado na deliberação de um sujeito, que já havia sido feita por Merce Cunningham (com quem Paxton dançou) e John Cage, quando estes passaram a usar procedimentos de sorteio ao acaso para compor, questionando e subvertendo a noção clássica de autor/compositor.

Tal desdobramento do questionamento da autoria e de ação se dá na medida em que a prática da pequena dança abre a possibilidade da experiência de um movimento que acontece no corpo, mas que não é "feito" pelo sujeito. Em outro trabalho, já citado (Penuela Sanches, 2018), discutimos algumas das implicações dessa experiência de consciência que testemunha e do movimento que não depende de uma ação. Aqui, no entanto, queremos salientar que essa investigação da percepção em um nível micro e da consciência como testemunha, juntamente com a valorização de uma atenção dilatada ao comum e ao básico associam-se a escolhas éticas e es-

8 Tal como discutimos em outro trabalho (Penuela Sanches, 2018). 
téticas que diferem radicalmente da valorização indiscriminada da velocidade e da aceleração, ou da tendência à intensificação e densificação da experiência sensorial.

Tais escolhas estéticas e éticas acarretam uma relação com o tempo que podemos aproximar da proposta de Byung-Chul Han (2016) de recuperação da "vida contemplativa", na medida em que promovem espaços e tempos de demorar-se e de não-fazer.

Além disso, trata-se de um posicionamento ético e estético que valoriza a sutileza.

A sutileza, como coloca Denise Sant'Anna (2001) abre espaços de sugestão, em lugar do direcionamento, e de enigma e ampliação de sentido, em lugar da imposição de uma verdade única ou da coerção. Nas palavras da autora:

O gesto sutil é em geral potente justamente porque sua força não se explicita de uma só vez, como se se tratasse do último ou do melhor gesto. [...]. Gestos sutis são delicados e fortes, por isso eles se parecem com formigas avermeIhadas que andam por toda a parte, como baratas ancestrais, uma sempre seguida da outra. Seres que parecem inúteis nesse mundo de tantas usuras. [...]. É que a sutileza, assim como a delicadeza, é fértil; elas sempre gestam outras falas e atos. São, portanto, coletivas e indicam passagens, criam envelopes, epidermes capazes de amaciar certos contatos e iniciar o corpo para a vida junto a muitos outros. A delicadeza constituinte do gesto sutil é iniciadora. (Sant'Anna, 2001, p. 125).

Além do demorar-se, a sutileza convida a formas de relação em que se ampliam as possibilidades de escuta e de contato com a alteridade e com o dissenso. A sutileza, nesse sentido, é uma das condições não apenas para certa maciez nos contatos, mas para o espanto, a dúvida, a abertura de sentidos, que convidam à escuta, assim como à construção de relações que possam apontar para um horizonte não de dominação, objetificação ou silenciamento, mas de troca e circulação.

\section{A questão da resistência (ou a resistência em questão)}

A palavra "resistência" tem sido uma das mais frequentemente usadas por movimentos sociais diversos para nomear sua posição e ação, sobretudo em contextos de recrudescimento do autoritarismo, de ataques ou perda de direitos.

$\mathrm{Na}$ Guerra Civil espanhola, na ocupação nazista na França, nas ditaduras militares na América Latina e em diversos outros contextos, a noção de resistência foi e segue sendo central para nomear formas de organização e de ação política de contraposição a certo status quo, de impedimento ou obstaculização de certos projetos ou ações (de dominação, de ocupação, de imposição etc.), assim como de sobrevivência e de continuidade de grupos ameaçados.

Trata-se, com efeito, de uma palavra complexa, polissêmica e que atravessa a história nomeando práticas e movimentos diversos.

Foge a nosso escopo neste texto fazer um exame crítico e histórico detalhado sobre a noção de resistência aplicada à política e aos movimentos sociais. Nosso interesse, no entanto, é abrir alguns espaços de reflexão a respeito dessa noção, in- 
dicando de que modo certas características da abordagem de movimento do Contato Improvisação permitem pensar formas de ação política e de enfrentamento de conflitos ou opressões não necessariamente melhores ou substitutivas das formas nomeadas pela palavra "resistência", mas que também mereceriam ser consideradas como parte importante do repertório de concepções da ação política.

Uma complexificação fundamental da noção de resistência aparece no primeiro volume da "História da Sexualidade" de Michel Foucault (publicado originalmente em 1976). Nas palavras deste autor, com a licença da longa citação:

Onde há poder, há resistência, e não obstante (ou melhor, por isso mesmo), esta nunca está em posição de exterioridade a respeito do poder. Deve-se dizer que se está necessariamente "no" poder, que não nos é possível "escapar" dele, que não há, em relação a ele, exterior absoluto, posto que se estaria infalivelmente submetido à lei? Ou que, sendo a história a astúcia da razão, o poder seria a astúcia da história - o que sempre ganha? Isso seria desconhecer o caráter estritamente relacional das relações de poder. Não podem existir senão em função de uma multiplicidade de pontos de resistência: estes desempenham, nas relações de poder, o papel de adversário, de branco, de apoio, de saliência para uma apreensão. Os pontos de resistência estão presentes em todas as partes dentro da rede de poder. A respeito do poder não existe, pois, um lugar do grande Rechaço - alma da revolta, foco de todas as rebeliões, lei pura do revolucionário. Mas há várias resistências que constituem exceções, casos especiais: possíveis, necessárias, improváveis, espontâneas, selvagens, solitárias, concertadas, rasteiras, violentas, irreconciliáveis, rápidas para a transação, interessadas ou sacrificiais; por definição, não podem existir senão no campo estratégico das relações de poder. Mas isso não significa que só sejam sua contrapartida, a marca de um vazio do poder, formando a respeito da dominação essencial um revés finalmente sempre passivo, destinado à indefinida derrota. As resistências não dependem de alguns princípios heterogêneos; mas nem por isso são engano ou promessa necessariamente frustrada. Constituem o outro termo nas relações de poder, nelas se inscrevem como irredutível elemento enfrentador. (Foucault, 1976/1998, p. 57)

As considerações de Foucault problematizam a noção de resistência, se pensada como simples modo de contraposição ou oposição a um poder delimitável e circunscrito. Em seu entendimento das relações de poder e da própria noção de poder, não estamos diante de um ou do poder de forma unívoca, mas de configurações móveis de relações de força que se dão em muitas camadas (que incluem instituições, um ordenamento do discurso, e modos de subjetivação).

Assim, o que pretendemos salientar do quadro construído por Foucault é sua consideração de que a(s) resistência(s) é(são) parte integrante das relações de poder, e além disso, que não há poder sem resistência e que as diferentes formas de resistência podem ser também pontos de ancoragem e de sustentação de formas de poder.

Como o autor enfatiza, isso não significa considerar que todas as formas de resistência estão apenas ou simplesmente a serviço do poder ${ }^{9}$ e que os movimentos

\footnotetext{
9 Apesar de em muitos momentos de seu livro usar "o poder" como um sujeito aparentemente monolítico em seus raciocínios, Foucault coloca que entende por "poder" uma multiplicidade complexa e muito móvel, definindo-o como: "a multiplicidade de relações de força imanentes e próprias do domínio em que se exercem, [...] o jogo que por meio de lutas e enfrentamentos incessantes as transforma, as reforça, as inverte; os apoios que essas relações de força encontram umas nas outras [...]; as estratégias, por último, que as tornam efetivas [...]." (Foucault, 1976/1998, p. 55)
} 
de contraposição, oposição, recusa etc. estão de antemão fadados ao fracasso. Mas, por outro lado, trata-se de notar que as relações de força que constituem o campo político são mais complexas do que uma contraposição linear entre dois entes homogêneos (do tipo opressor contra oprimido) e que muitas vezes, o que entendemos como resistência e contraposição (inclusive por exemplo o que dissemos no item anterior sobre a sutilização e a dilatação do tempo), pode ocupar papéis diversos ou ambíguos, cabendo a cada ator político compreender que o valor estratégico e a eficácia política (no sentido da possibilidade de produzir efeitos) de determinado gesto, princípio ou discurso não são unívocos e lineares, e podem mudar conforme muda a configuração das relações de força que constituem o que Foucault denomina "poder".

Sendo assim, tendo em vista as ambiguidades e complexidades das relações entre poder e resistência que sua análise aponta, seria em geral necessário e estratégico interrogar, sem pressupor uma resposta linear e simples, até que ponto determinado gesto ou movimento de denúncia, contraposição, repúdio ou reação pode, dentro de determinado contexto, contribuir como um ponto de ancoragem e fortalecimento justamente do movimento ou do discurso que se pretendia a princípio combater. Em outras palavras, interrogar quando, em que momentos e de que modos gestos ou movimentos de resistência resultam no que pretendem e quando, em que momentos e de que modos acabam por fortalecer aquilo que esperam combater.

Voltando ao Contato Improvisação, penso que alguns elementos de sua abordagem da corporeidade e do movimento podem contribuir para a reflexão sobre os sentidos estratégicos de certas formas de agir e ampliar o repertório de modos de conceber a ação política, as relações de força, e o enfrentamento de conflitos.

Um primeiro aspecto está relacionado aos resultados das investigações com as colisões, que constituíram a performance Magnesium. O que se verificou naquela pesquisa é justamente que, em uma colisão, existem modos de modular o tônus que favorecem o encontro de soluções seguras para possíveis esmagamentos, pressões, contusões etc. A hipertonia e o uso da força dos músculos superficiais - que é muitas vezes a qualidade de um corpo pronto a resistir - tendem a impedir a percepção e a sintonização com a gravidade (já que a musculatura mais superficial passa a estruturar a postura, constituindo o corpo como um bloco sólido), impedindo deste modo que o corpo perceba, nas frações de segundo decisivas, os caminhos e fluxos que melhor distribuem o impacto ou que melhor conduzem a massa ao chão, numa queda.

A possibilidade de cultivar uma consciência que não somente age, mas também testemunha, tal como discutimos anteriormente, assim como de abrir-se ao saber dos reflexos e movimentos pré-voluntários (ou sutis ou rápidos demais para serem controlados pela consciência que decide como mover-se) implica o acesso a um conjunto mais amplo de respostas e saídas para situações de pressão, conflito, diminuição do espaço etc.

Isso não significa a defesa de uma atitude "paz e amor", da não-ação, da espera ou do relaxamento como atitudes que servem a todas as situações ou que são sempre melhores que o aumento do tônus, a deliberação e o uso da força. Significa compreender que, assim como ampliar a diversidade de combinações e variações 
do tônus muscular permite uma maior gama de possibilidade e qualidades de ação e movimento, ampliar a diversidade de concepções sobre quem é o sujeito político que age, como e quando agir e como incluir na ação a complexidade de forças e processos que constituem o contexto e que o excedem também amplia a efetividade e os sentidos estratégicos de determinado gesto ou posicionamento político.

A investigação sobre as colisões mostrou a importância da percepção do campo de forças que atravessam e constituem o corpo em uma dada configuração material no tempo. Além da massa individual e dos movimentos voluntários de um corpo, sua capacidade de sentir e sintonizar-se com essa fisicalidade complexa do mundo, que o excede e que também o constitui é decisiva para a descoberta de recursos e caminhos possíveis para uma resolução que o preserve sem ferimentos.

Ampliando esse princípio, pode-se pensar que a ação política se enriquece e amplia seus recursos quando o sujeito político não é pensado somente com base em uma noção de ação deliberada e individual, mas podendo sintonizar-se com o conjunto complexo de forças que o atravessam e o constituem e com processos mais amplos dos quais sua existência faz parte em cada momento.

Além disso, outro aspecto do $\mathrm{Cl}$ que traz elementos para refletir sobre a noção de resistência (quando pensada em associação com a força e deliberaço de um indivíduo ou grupo), refere-se à influência decisiva da arte marcial japonesa Aikidō sobre seus princípios de movimento.

O Aikidō é uma arte marcial desenvolvida por Morihei Ueshiba (1883-1969) nas primeiras décadas do século $X X$, e que influenciou decisivamente o trabalho de Paxton. Alguns de seus princípios de movimento, sobretudo aqueles manifestos nos rolamentos (ukemi), o fascinaram bastante por sua efetividade e diferença em relação aos princípios das técnicas de dança que ele conhecia até então, de modo que fizeram parte do material trabalhado no workshop que resultou em Magnesium, bem como em todo o desenvolvimento do $\mathrm{Cl}$ dos anos 1970 em diante ${ }^{10}$.

Um princípio importante sobre como essa arte marcial aborda situações de conflito, sobretudo quando há desigualdade de força nos corpos em jogo, aparece nas palavras de Kisshomaru Ueshiba:

O que posso fazer quando confrontado com alguém fisicamente mais forte do que eu mesmo? [...]. Em uma palavra, como podemos desenvolver uma defesa contra alguém superior em tamanho, força e experiência? O princípio e a aplicação da rotação esférica como base do Aikidō foi originado pelo Mestre Ueshiba em resposta a este tipo de questões e foi desenvolvido como um desafio para as artes marciais tradicionais. O princípio de que o suave controla o duro, o flexível conquista o rígido, encontrado no jüjutsu foi herdado pelo Mestre Ueshiba em sua formulação do Aikidō, mas com uma diferença fundamental. No antigo jüjutsu ensinavam que "quando empurrado, puxe; quando puxado, empurre para frente". Nos movimentos esféricos do Aikidō, isto se torna "quando empurrado, gire ao redor; quando puxado, entre enquanto circula". Isso significa que nos movemos em movimento circular em resposta ao oponente e enquanto nos movemos esfericamente, mantemos o centro de gravidade para criar um eixo estável de movimento. Ao mesmo tempo, o centro do oponente é perturbado, e quando ele perde seu centro, ele perde também seu poder (Ueshiba, 1984, p. 40-41).

\footnotetext{
${ }^{10}$ Cf. textos de Steve Paxton sobre o Aikidō no volume 5 da revista Contact Quarterly, 1980
} 
A descrição feita por Ueshiba de como no Aikidō uma situação de conflito e desigualdade é manejada pela busca por movimentos esféricos, pela flexibilidade e pela sintonia com o centro de gravidade evidencia que as respostas a situações de conflito ou opressão podem ser mais complexas que a mera ideia de exercer uma contraforça de resistência e que a própria noção de resistência pode se complexificar, por exemplo, quando entram em jogo questões sobre o sentido do movimento (esférico ou linear?), os eixos em torno do qual ele ocorre e como o próprio conflito é concebido.

O que poderia significar, em um contexto político e coletivo, encontrar um eixo de gravidade ou "girar ao redor, quando empurrado"? É um tipo de interrogação que poderia ampliar os sentidos da ação política e o repertório de modos de responder a algumas situações opressivas.

\title{
Ruptura com o imperativo da produtividade
}

A aceleração do tempo e a intensificação de estímulos e informações, que discutimos anteriormente, são diretamente relacionadas a uma economia e cultura baseadas no crescimento da produção, do consumo e do lucro como valores praticamente inquestionáveis.

Já ao final do século XIX, com a consolidação crescente da industrialização, a crítica ao imperativo da produção, do trabalho e a uma economia baseada no lucro e na concentração ilimitada de riquezas se fez de maneira bastante contundente.

Henry David Thoreau (1817-1862), por exemplo, criticando o excesso de tarefas e de trabalho que caracterizava a vida das pessoas em sua cultura, propôs-se viver um ano sozinho à beira da lagoa Walden, mostrando que era possível sobreviver reduzindo seu trabalho à satisfação das necessidades mais básicas e simplificando ao máximo a vida cotidiana. Em suas palavras:

\begin{abstract}
A maioria dos homens, inclusive neste país relativamente livre, por mera ignorância e erro, está tão ocupada com os cuidados fictícios e os labores superfluamente grosseiros da vida, que não pode colher seus melhores frutos. [...]. Na realidade, o homem laborioso não tem ócio para uma verdadeira integridade cotidiana. [...]. Não tem tempo de ser senão uma máquina. (Thoreau, 1854/2006, p. 64)
\end{abstract}

Paul Lafargue, algumas décadas depois, coincidiria no diagnóstico feito por Thoreau em relação à sociedade e à vida em sua época, criticando o modo como o excesso de trabalho e a cultura do trabalho conduziam à miséria, à acumulação de riquezas, à desigualdade e a um círculo vicioso em que quanto mais produziam riqueza, mais os trabalhadores eram coagidos a precisar trabalhar. Em suas palavras:

Trabalhem, trabalhem, proletários, para aumentar a fortuna social e as vossas misérias individuais, trabalhem, trabalhem, para que, tornando-vos mais pobres, tenham mais razão para trabalhar e para serem miseráveis. Eis a lei inexorável da produção capitalista. Porque, ao prestarem atenção às insidiosas palavras dos economistas, os proletários se entregaram de corpo e alma ao vício do trabalho, precipitam toda a sociedade numa destas crises de super- 
produção que convulsionam o organismo social. Então, porque há superabundância de mercadorias e penúria de compradores, as oficinas encerram e a fome fustiga as populações operárias com o seu chicote com mil loros. Os proletários, embrutecidos pelo dogma do trabalho, não compreendem que é o supertrabalho que infligiram a si próprios durante o tempo da pretensa prosperidade a causa da sua miséria presente. (Lafargue, 1880, p. 7)

A combinação entre excesso de trabalho e de produção junto à redução de liberdade e miséria, que já era observada por Thoreau e Lafargue no auge da industrialização no século XIX, segue sendo uma característica de nosso tempo, mais de um século depois.

Em relação, por exemplo, à realidade material mais básica, a alimentação, chegamos a um estágio da história em que a produção atual de alimentos no mundo, segundo a Food and Agriculture Organization da ONU, já é maior do que o necessário para suprir as necessidades alimentares de toda a população mundial, mas ainda assim, 821 milhões de pessoas passam fome no mundo, segundo a mesma organização, enquanto são desperdiçadas 1,6 bilhão de toneladas de alimento por ano no planeta ${ }^{11}$.

Em um contexto em que apesar do aumento da produção e da produtividade (capacidade de produzir mais em menos tempo e com menor custo), segue existindo miséria e milhões de pessoas seguem sem acesso a bens básicos, e em que o avanço da mecanização e das possibilidades de as máquinas substituírem o trabalho humano não acarreta na prometida liberação do tempo para o ócio ou outras atividades, o questionamento da valorização do trabalho e da exploração do trabalho segue sendo necessário, mesmo que, evidentemente, as leituras das causas dessa realidade sejam bastante controversas e diversas.

De um modo geral, a dança não tem formulado a pretensão de oferecer respostas a essas contradições ou questões econômicas amplas e complexas, no entanto, cabe salientar que já no começo do século XX ela chamava a atenção de alguns teóricos e filósofos justamente pelo fato de ser uma atividade humana em que é empregada muita energia e tempo, sem no entanto, a princípio, haver nenhuma finalidade de produzir um produto externo ou satisfazer alguma necessidade utilitária.

Paul Valéry (1938/2003, p. 34), por exemplo, enfatiza o fato de a dança ser uma forma de movimento cuja "motivação é intrínseca" e não voltada a fins externos a ela mesma.

Já contemporaneamente, Susan Leigh Foster (2016) discorre sobre uma pergunta que põe em evidência as questões que a dança traz para uma economia e uma sociedade baseadas na produtividade, qual seja, "por que sempre há energia para dançar?"

Excluindo alguns usos que Foster considera empregos excepcionais da dança (como quando há coerção para dançar ou quando a dança é vivida como um trabalho de rotina, repetitivo e intensificado por demandas comerciais etc.), em compa-

\footnotetext{
11 Fontes dessas informações:

https://exame.abril.com.br/mundo/desperdicio-de-alimentos-no-mundo-pode-aumentar-30-ate-2030/

https://www.nexojornal.com.br/explicado/2016/09/02/Mundo-produz-comida-suficiente-mas-fome-ainda-\%C3\%A9-uma-realidade

http://www.fao.org/americas/noticias/ver/pt/c/1152189/
} 
ração com muitas das atividades humanas ligadas ao trabalho, que costumam ser seguidas de cansaço e esgotamento, a dança, para a autora, tende a ser vivida como uma atividade "autogenerativa", no sentido de que, independentemente de qualquer ganho utilitário, amiúde as pessoas seguem querendo dançar e seguem dançando por horas, e ao longo dessas horas seguem sentindo-se mobilizadas e com energia para continuar.

O que faz com que essa forma de movimentação, que também demanda trabalho, no sentido físico do termo, tenda a ser vivida de uma maneira tão diversa das formas de movimentação utilitária que, se não forem seguidas de algum tipo de recompensa exterior (o salário, a produção de um bem vendável, etc.) cessariam de acontecer? Foster (2016) retoma diferentes teorias sobre a dança, discutindo aspectos como a ludicidade, o estabelecimento de relações sociais, e a potência de subjetivação do corpo como possíveis características da dança que, se não respondem à pergunta de partida, dão pistas sobre como encaminhá-la.

De todo modo, como coloca essa autora, a dança tem uma "generatividade" própria, que aponta para uma concepção de economia e de relação entre o ser humano e a vida não baseada em uma lógica de escassez, que leva à ideia de que é preciso sempre produzir mais, acumulando e concentrando recursos, mas, por outro lado, baseada em uma lógica de abundância e compartilhamento.

A questão da abundância é complexa e mereceria uma discussão mais detalhada a respeito ${ }^{12}$ (até porque é facilmente mal-entendida ou capturável por discursos interessados em manter um status quo desigual), que também foge ao nosso escopo. De todo modo, a existência e a continuidade de fenômenos como a dança - em que uma grande quantidade de energia é dispendida sem a necessidade de uma recompensa ou produção externa e sem uma utilidade imediata em relação a necessidades de produção ou reprodução - problematiza uma concepção utilitarista de ser humano, baseada no pressuposto da produção e do ganho ou vantagem como motivações primárias ou únicas da ação humana ${ }^{13}$.

Por outro lado, a conformação da dança como uma profissão, a partir do desenvolvimento do balé clássico, complica esse circuito, na medida em que introduz o dançar em um economia comercial na qual dançarinos e coreógrafos passam a atuar não somente ou não principalmente pela "motivação intrínseca", mas também para oferecer seu produto (a performance e a coreografia) em uma rede de trocas monetárias, com suas pressões e demandas próprias.

O Contato Improvisação, no entanto, tendo surgido em um contexto de forte profissionalização da dança, recoloca em questão as relações entre dança, economia e produção, pois, por um lado, ao apostar na improvisação, implode o lugar da coreografia como um produto estável e reprodutível, que pode, portanto, ser comercializado tanto quanto qualquer outro objeto de arte $^{14}$. E ainda, ao mesmo tempo em

\footnotetext{
12 Em relação a essa discussão, faço referência por exemplo a Caldeira, 2015 e Latouche, 2012.

${ }^{13}$ O Movimento Antiutilitarista em Ciências Sociais (MAUSS) desenvolve essa discussão sobre a possibilidade de uma antropologia não baseada em noções como interesse, ganho ou utilidade de certa ação ou fenômeno cultural. Para uma apresentação de suas ideias, cf. Martins, 2008.

14 Muitas são as discussões que procuram questionar e complexificar as fronteiras entre improvisação e coreografia. Bardet (2014), que citamos anteriormente, por exemplo, tece várias considerações importantes problematizando essa distinção quando feita de maneira demasiado reificada. No entanto, em relação ao tema das relações entre dança e produção (de produtos), a improvisação, mesmo que ainda possa ser vendida (no sentido de que é possível contratar uma
} 
que é uma forma de dança que segue sendo feita por profissionais e acontecendo em performances com uma divisão clara entre público e dançarinos, também cria e difunde espaços e dispositivos de prática que borram essa divisão, e que introduzem um caráter social e não-profissional ao espaço da dança como forma de arte.

As chamadas Jams ${ }^{15}$ de Contato Improvisação, que se desenvolveram desde os anos 1970 e seguem sendo espaços fundamentais onde acontece o $\mathrm{Cl}$, por exemplo, são espaços de prática em que dançarinos profissionais ou não, com diferentes níveis de experiência, encontram-se para dançar, imbricando performatividade a aspectos sociais diversos, como o estabelecimento de relações, a exploração da comunicação não-verbal entre corpos, a ludicidade, aspectos terapêuticos ou várias outras implicações e motivações para o dançar.

Uma das consequências da difusão das Jams e mesmo do tipo de performance informal e improvisacional que caracteriza o $\mathrm{Cl}$ é justamente a difusão e democratização da autonomia e da potência de dançar, sobretudo em certos espaços culturais onde apenas a dança profissional, e ainda virtuosística, seria digna e valorizável, ou mesmo autorizada a acontecer. Nas palavras de Cynthia Novack a esse respeito: "a estrutura do Contato Improvisação fez possível teoricamente que todos os participantes sentissem que podem dançar, independentemente de um coreógrafo ou diretor" (Novack, 1990, p. 206). A respeito desse aspecto, o depoimento do dançarino Arnie Zane é bastante significativo: "o contact me permitiu dançar. Ele me disse: 'okay, o corpo que você tem está bem. Não há nada mal que você possa fazer uma vez que chegue ao chão'" (Arnie Zane, citado por Novack, 1990, p. 178).

\section{Redefinições da experiência comunitária e da articulação}

Para terminar, um elemento importante a se salientar é o modo como o Contato Improvisação difunde-se e desenvolve-se com base em certa articulação entre praticantes que não configura uma comunidade no sentido tradicional do termo, mas que aponta possibilidades de vínculo coletivo e construção de espaços de troca bastante importantes de serem examinadas.

Na cidade de São Paulo, em geral, as Jams de Contato Improvisação terminam com rodas abertas onde as pessoas são convidadas a falar o que quiserem sobre a experiência, a fazer questões, dar depoimentos etc. Ao longo de mais de uma década organizando e frequentando Jams nessa cidade, observo com muita frequência aparecer nas rodas finais o enunciado de que a Jam é um espaço de respiro e de refúgio em contextos vividos como muito opressivos (por conta das pressões do espaço urbano, do mundo do trabalho, da economia capitalista, da cultura machista e racista etc.).

performance de improvisação tanto quanto uma coreográfica) acarretou de início problemas para ser reconhecida como um produto artístico, e de fato muitos de seus praticantes, sobretudo o próprio Paxton, escolhem-na deliberadamente como um modo de criar ruídos e problemas nas instituições e no sistema de comércio de dança. Em uma palestra em Bruxelas em 2019, Paxton por exemplo declarou que considera a improvisação insustentável para o sistema atual de economia da dança e uma prática anticapitalista. Uma discussão mais detalhada sobre essa questão pode ser encontrada em Novack, 1990 , cap. 9.

${ }^{15}$ A versão mais difundida sobre a origem desse termo é que se trata de uma referência à expressão Jazz After Midnight, que nomeia encontros de músicos de jazz que se reúnem para improvisar, ao longo da noite. 
Outros espaços e formas de organização podem funcionar para diferentes pessoas como lugar de refúgio, por exemplo espaços ligados à vida religiosa, a movimentos sociais, grupos terapêuticos, entre outros. O que cabe salientar no entanto é de que modo o espaço da Jam sustenta-se coletivamente e é vivido por tantas pessoas como um lugar de apoio, acolhimento e abertura de possibilidades de subjetivação, sensibilização e investigação da corporeidade que depende de muito poucos signos ou compromissos de filiação ou identificação mútua e que teoricamente não tem pré-requisitos técnicos para a participação. Assemelha-se a um espaço ritual, à festa ou ao baile, no entanto, não estabelece papeis aos dançarinos (do tipo, homens que devem conduzir e mulheres que devem ser conduzidas, por exemplo), tampouco depende do conhecimento, por parte de todos, de um código ou repertório comum (como por exemplo os passos de determinada dança, ou as etapas de um ritual coletivo partilhado). Evidentemente, há técnicas e certo vocabulário que caracterizam o Contato Improvisação, sobretudo com o passar dos anos e a sedimentação de certos esquemas e soluções motoras valorizados e repetidos pelos praticantes (como sendo úteis, eficazes, belos etc). No entanto, no espaço da Jam, cada par ou grupo de pessoas que se engajam em uma improvisação conjunta pode desenvolver uma dança singular, investigando e explorando o que escolher explorar, dentro de um enquadramento que existe, mas é bastante aberto.

Essa abertura do enquadramento de uma Jam cria um tipo de experiência de comunidade (no sentido da partilha de algo comum) bastante sui generis, na medida em que há abertura suficiente para muitas diferenças e aspectos não compartilhados, ao mesmo tempo em que há convivência e co-presença em um espaço comum. Diferente de uma comunidade baseada na identificação mútua (mesmo que muitas vezes essa também possa ser uma característica dos praticantes do Contato Improvisação, sobretudo os mais experientes e identificados com a noção de "contateiro"), o espaço das Jams cria uma espécie de comunidade provisória, mas que, apesar de muito móvel, é bastante consistente e autoorganizativa, já que este dispositivo tem durado e se difundido crescentemente pelo mundo há mais de quatro décadas.

Essa forma de comunidade tem alguns elementos que podem se assemelhar a aspectos apontados pelo Comitê Invisível (2014) sobre as situações em que movimentos sociais surgiram sem depender de uma liderança ou de instituições e deliberações feitas em assembleia, encontrando no correr da experiência modos de autogestão muito eficazes, baseados em um tipo de compartilhamento que não pressupõe o consenso, a hierarquização ou uma identidade comum, mas a co-presença de diferentes e a sintonização mútua com certa sensibilidade partilhada. Nas palavras desses autores, "organizar-se jamais quis dizer afiliar-se à mesma organização. Organizar-se é atuar segundo uma percepção comum, ao nível que seja" (Comitê Invisivel, 2014, p. 18).

É notável que o Contato Improvisação tenha se expandido ao longo das suas poucas décadas de existência a partir de uma escolha deliberada de seus criadores de não criar nenhum tipo de instituição central, nenhum tipo de formação oficial ou de distinção entre formados e não-formados, autorizados e não-autorizados. A articulação entre os praticantes, coerente com os valores políticos, éticos e estéticos que os princípios dessa forma de dança apontam, deu-se desde as primeiras décadas com 
base em uma rede de trocas, na qual a revista Contact Quarterly teria um papel chave mas não hierarquicamente superior (até porque trata-se de uma revista também muito aberta, onde são publicados pontos de vista diversos e cada vez mais assuntos sobre o corpo, a dança e a educação somática que ultrapassam a esfera do que seria o Contato Improvisação).

Três aspectos das insurreições contemporâneas que, ao mesmo tempo, são modos de compreender a ação política, propostos pelo Comitê Invisível, parecem estar presentes no Contato Improvisação e nesse sentido, fazem dele um exemplo potente (mas não, obviamente, um modelo) para se refletir sobre a articulação política e possíveis sentidos contemporâneos do coletivo.

Um destes aspectos é a noção de "verdades éticas", que, nas palavras do Comitê Invisível, "não são verdades sobre o Mundo, mas verdades a partir das quais nos mantemos nele. São verdades, afirmações, enunciadas ou silenciosas, que se experimentam, mas que não se demonstram" (Comitê Invisível, 2014, p. 49). Outro aspecto é a ênfase em uma "política da atenção e da sensibilidade", no sentido em que "é por meio da atenção aos fenômenos, por meio de suas qualidades sensíveis, como chegarão a devir uma potência real" (Comitê Invisível, 2014, p. 204-205). E por fim o entendimento de que os indivíduos são "potências em situação" e que a ação política se potencializa, na medida em que se expande sem recorrer a uma centralidade (Comitê Invisível, 2014, p. 243), baseando-se justamente na força dos encontros e trocas impossíveis de se pré-definir.

\section{Considerações finais}

A intenção principal deste trabalho foi salientar que algumas características e princípios da forma de dança denominada Contato Improvisação têm implicações relevantes para uma reflexão sobre alguns dos principais problemas da ação e do pensamento político contemporaneamente.

Evidentemente, não pretendemos afirmar, com isso, que essa forma de dança pode ou deve ser tomada como modelo ou receita de ação política ou que esteja desprovida de problemas e contradições, ou imune às opressões e injustiças estruturais que constituem as sociedades onde ela se desenvolveu e segue se desenvolvendo.

A descrição do espaço da Jam, por exemplo, como um espaço aberto a formas de articulação coletiva e interpessoal baseadas no compartilhamento de uma sensibilidade comum ou de verdades éticas não implica, com efeito, pressupor que não podem ocorrer ou que não ocorram formas de racismo, machismo, homofobia, reprodução de desigualdades e opressões em Jams e em coletivos praticantes de $\mathrm{Cl}$, ou que se trate de um espaço que podemos idealizar, e que serve como inspiração ou modelo universal, aplicável a qualquer contexto, cultura, situação histórico-geográfica, etc.

Não se pretende com esse texto louvar ou vender o Contato Improvisação como resposta para problemas altamente complexos e contradições difíceis em relação à ação e à realidade política, mas apontar e sublinhar que seus princípios e modos de acontecer podem ser potentes para problematizar e refletir aspectos especí- 
ficos da ação política e das injunções entre arte e política, escolhas estéticas e éticas, e implicações políticas de certas concepções de sujeito e de corpo e as poéticas que a elas correspondem.

\section{Referências}

BANES, S. Terpsichore in sneakers: post-modern dance. Middletown: Wesleyan University Press, 1987.

BARDET, M. A Filosofia da Dança. São Paulo: Martins Fontes, 2014.

BAUMAN, Z. Modernidad liquida. México DF: Fondo de Cultura Económica, 2000.

BENJAMIN, W. Experiência e pobreza. In: Obras escolhidas: Magia e técnica, arte e política. São Paulo: Brasiliense, 1994. (Originalmente publicado em 1933)

BENJAMIN, W. O narrador: considerações sobre a obra de Nicolai Leskov. In: Obras escolhidas: Magia e técnica, arte e política. São Paulo: Brasiliense, 1994 (Originalmente publicado em 1936)

BERMAN, M. Tudo o que é sólido desmancha no ar: a aventura da modernidade. São Paulo: Cia das Letras, 1986.

CALDEIRA, J. A teoria do valor Tupinambá. Folha de São Paulo. 31/05/2015.

Disponível em:

https://www1.folha.uol.com.br/ilustrissima/2015/05/1635380-a-teoria-do-valor-tupinamba.shtml

COMITÉ INVISIBLE. A nuestros amigos. Logroño: Editorial Pepitas de Calabaza, 2014.

FOSTER, S. L. Why is there always energy for dancing. Dance Research Journal. Vol. 48, n. 3, Cambridge, 2016.

FOUCAULT, M. Historia de la sexualidad: Vol. 1 - La voluntad de saber. Madrid/México D.F.: Siglo Veintuno, 1998.

GIL, J. Movimento total: o corpo e a dança. São Paulo: Iluminuras, 2004.

HAN, B.-C. O aroma do tempo. Lisboa: Relógio d’Água, 2016.

INNERARITY, D. The future and its enemies: in defense of political hope. Stanford: Stanford University Press, 2012.

LAFARGUE, P. O direito à preguiça. 1880. Publicação online por: The Marxists Internet Archive. Disponível em: https://www.marxists.org/ 
LATOUCHE, S. Como construir uma nova sociedade da abundância. Revista do Instituto Humanitas Unisinos. 19/09/2012. Disponível em:

http://www.ihu.unisinos.br/noticias/513716-como-construir-uma-nova-sociedade-da-abundancia-artigo-de-serge-latouche

LOUPPE, L. Poética da dança contemporânea. Lisboa: Orfeu Negro, 2012.

MARTINS, P. H. De Lévi-Strauss a M.A.U.S.S. - Movimento Anti-Utilitarista nas Ciências Sociais: itinerários do dom. Revista Brasileira de Ciências Sociais. Vol. 23, n. 66. São Paulo, 2008. Disponível em:

http://www.scielo.br/scielo.php?script=sci_arttext\&pi$\mathrm{d}=\mathrm{S} 0102-69092008000100007$

NOVACK, C. J. Sharing the Dance: Contact Improvisation and American Culture. Madison: The University of Wisconsin Press, 1990.

PAXTON, S. Drafting interior techniques. In: SMITH, N. S. (org.) Contact Quarterly's Contact Improvisation Sourcebook vol. 1. Northampton (MA, EUA): Contact Editions, 1997.

PAXTON, S. A Definition. Contact Quarterly. Winter 1979, p. 26.

PAXTON, S. Excerpts from Steve Paxton's talk at Cl 36. Contact Quarterly. Winter/ Spring 2009. Northampton: Contact Editions, 2009.

PENUELA SANCHES, P. R. Corpo-outro: paradoxos da corporeidade na Contact Improvisation. Urdimento. Vol. 1, no. 24. Florianópolis, 2015. Disponível em:

http://www.revistas.udesc.br/index.php/urdimento/article/ view/1414573101242015197

PENUELA SANCHES, P. R. Encontro entre corpos: um estudo sobre o corpo por meio do diálogo entre a dança Contato Improvisação e a psicanálise winnicottiana. Dissertação de mestrado. Instituto de Psicologia da Universidade de São Paulo (IP-USP). São Paulo, 2012. Disponível em:

https://teses.usp.br/teses/disponiveis/47/47133/tde-07052012-175206/pt-br.php

PENUELA SANCHES, P. R. Das relações entre dança e movimento: reflexões sobre diferentes noções de movimento e a dança. Revista Brasileira de Estudos da Presença. Vol 8, no. 3. Porto Alegre: 2018. Disponível em:

https://www.seer.ufrgs.br/presenca/article/view/73443

SANT'ANNA. D. B. (2001). Corpos de passagem: ensaios sobre a subjetividade contemporânea. São Paulo: Estação Liberdade, 2001. 
SIMMEL, G. A metrópole e a vida mental. In: VELHO, O. (org.). O fenômeno urbano. Rio de Janeiro: Zahar, 1973. (Originalmente publicado em 1902)

THOREAU, H. D. Walden: life in the woods. Princeton: Princeton University Press, 2004. (Originalmente publicado em 1854)

UESHIBA, K. The spirit of Aikido. Tokyo/New York/San Francisco: Kodansha International, 1984.

VALÉRY, P. Degas Dança Desenho. São Paulo: Cosac \& Naify, 2003. (Originalmente publicado em 1938)

Recebido em: 18/09/2019

Aprovado em: 20/11/2019 